\title{
PACKING ISSUE IN CEMENT BLENDING FOR SUSTAINABILITY DEVELOPMENTS - APPROACH BY DISCRETE ELEMENT METHOD
}

\author{
Nghi L.B. Le ${ }^{1}$, Piet Stroeven ${ }^{2}$ \\ ${ }^{I}$ Delft University of Technology, Faculty of Civil Engineering and Geosciences, Delft, the Netherlands \\ ${ }^{2}$ Delft University of Technology, Faculty of Civil Engineering and Geosciences, Delft, the Netherlands
}

\begin{abstract}
Common cement blending materials for concrete like fly ashes, blast furnace slag, silica fume, metakaolin and rice husk ash have been investigated experimentally as to their impact on concrete's mechanical, physical and sustainability capabilities. Such efforts offer but case-related information on involved materials and used procedures. Generalizations will be difficult because also contradicting information is provided: a weak basis to guide further developments. Published research data on blends with inert components (carbon black) confirm fineness to be the leading parameter governing their mechanics. Experimental efforts revealing blending effects on durability issues are more scarce because of their complicated, laborious and time-consuming nature. Hence, generalization capabilities are even more restricted. An approach is therefore presented for studying cementitious materials in the virtual reality, employing the concurrent algorithm-based dynamic discrete element method (DEM), HADES. Hydration simulation of the simulated (blended) Portland cement grain mixture is thereupon accomplished with an extended version of the vector approach. Robotics-based pore delineation provides topological information, while geometric characterization of the pore networks is accomplished by star volume measurements. Topological and geometric parameters can be combined in a hydraulic model for durability estimation. This approach allows covering a wide range of parameters. This would render possible more systematic and economic development of such materials for sustainability purposes, among other things. The production stages (DEM and hydration simulation) and the analysis stages (pore delineation and topology and geometry assessment) are briefly outlined. Application of the methodology is illustrated on finer and coarser grained cements blended with rice husk ash produced with different fineness. The effects of the gap in grading on the pore network characteristics relevant for transport-based durability items are outlined.
\end{abstract}

Keywords: Cement blending, particle packing, hydration, discrete element method, porosimetry, transport-based durability.

\section{INTRODUCTION}

Common cement blending materials for concrete like fly ashes, blast furnace slag, silica fume, metakaolin and rice husk ash have been investigated experimentally as to their impact on concrete's mechanical, physical and sustainability capabilities. Such efforts offer but case-related information on involved materials and used procedures. Generalizations will be difficult because also contradicting information is provided. This constitutes a weak basis to guide further material developments that would fulfil sustainability requirements. Portland cement production significantly contributes to worldwide $\mathrm{CO}_{2}$ emissions [1]. Hence, partial replacement of Portland cement (PC) by waste components would have direct positive sustainability effects. In that respect, the calcined clays can be added to the aforementioned list as artificial pozzolanas. Kaolinite, thus obtained, derives its potentialities primarily from the metakaolin it contains. The commercial metakaolin is much finer, however also (far) more expensive. Yet, fineness plays an important role in all blends. In the same way the kaolin is calcined, diatomite can be obtained in amorphous state when properly produced, but it contains smaller amounts of alumina. Yet, for identical production conditions (including the grinding period) we found about similar strength in comparable situations due to the finer-grained diatomite [23]. All these blending components manifest natural or artificial pozzolanic properties that can compensate for the reduced chemical potentials of the PC in the blend. Published research data on blends with inert components (carbon black) con-firm fineness to be the leading parameter governing their mechanics [4]. With the fineness of the carbon black attuned to that of the Portland cement (so, leading to optimum packing), it was found that in the high quality range the reduced chemical capabilities could be fully compensated by the physical contributions to strength.

Experimental efforts revealing blending effects on durability issues are scarcer because of more complicated, laborious and time-consuming nature. As an example, see [5-6]. Yet, it becomes apparent from the literature that more efficient binder packing in the fresh state will lead to a denser hydrate structure and thus reduced pore dimensions [7]. This would make the concrete less accessible for both gasses and fluids that are harmful to concrete's integrity. So, particle packing should be considered a relevant issue in designing blends for promoting sustainability, among other things [8].

Generalizations can nowadays more easily be made by studying virtual cementitious materials [9-15]. Of course, 
the reliability of the research outcomes will depends on the quality -for the objected purpose- of the simulation system [16]. The popular random sequential addition (RSA) systems in concrete technology should be avoided, since pore network characteristics will depend on the particle dispersion in the virtual material. This is biased in RSA systems [17-18]. Hence, DEM, either of static or of dynamic nature, should be selected for the present purpose. DEM simulations by a versatile system like HADES make it possible producing realistic representations of cementitious materials on different structural levels. Aggregate grains of fluvial origin or of crushed rock can be packed according to respective sieve curves into the dense random packing state [19]. Such experiments on meso-level yield information on surface spacing and thus on the extent of the binder that is pocketed between the aggregate surfaces. On micro-level the binder grains are thereupon packed in containers of appropriate size. Two rigid container surfaces may represent the aggregate surfaces that induce gradient structures, which are denoted as Interfacial Transition Zones (ITZs) [20-21]. Next, hydration simulation is accomplished by an extended version of the vector approach [22]. Robotics-based pore delineation provides topological information, while geometric characterization of the pore network is accomplished by star volume measurements [14,23]. Topological and geometric parameters can be combined in a hydraulic model for durability estimation. This approach renders possible covering in an economic way a wide range of parameters. This paper will apply the sketched DEM approach to gap-graded RHA blends, whereby the gap is varied in intensity.

\section{METHODOLOGY IN VIRTUAL REALITY}

The details of the various blocks of the methodology for porosimetry are explicitly described in the international literature. Successively, these blocks concern

1) HADES: dynamic DEM for packing simulation of artificially-shaped particles on meso-, micro- and nano-level [19];

2) XIPKM: extended integrated particle kinetics method for simulation of fresh multi-component blended cement system [22]; the IPKM reference method is described in [12,24];

3) DRaMuTS: double random multiple tree structuring system for delineating the complete pore network system and for topology assessment [14];

4) SVM: star volume measurements in uniformly random point system inside the pore network $[14,23]$;

5) Tube model: the tree data obtained by DRaMuTS are employed to construct a network of cylindrical tubes connected at nodes that represents the percolated pore system; by applying a pressure gradient across the ends of the network, permeability is determined $[13,25]$.

Hence, interested readers can find all computational details on algorithms in the indicated international literature.
Globally speaking, the sequence of activities encompassed the following. A Rosin-Rammler function is specified to repre-sents the size distribution of the Portland cement; i.e., $\mathrm{G}(d)=1-\exp \left(-\mathrm{b} d^{\mathrm{a}}\right)$, whereby $\mathrm{G}(\mathrm{d})$ stands for the mass or volume fract-ion of the cement passing a sieve with opening $d$, and $\mathrm{a}$ and $\mathrm{b}$ are constants [26]. Mineral admixture particles may have their own grain size distribution. The amount of particles necessary to achieve pre-determined water to binder ratio and blending percentage is assessed and dispersed by RSA in a large container, generally with two rigid and four periodic boun-daries. Particles are set to linearly move and rotate according to Newtonian rules. Overlap is avoided by having a thin boundary layer of constant thickness enveloping the particles.

Local overlap of such boundary zones activates associated surface elements of the particles. Depending on total involved surface area and degree of overlap, an integrated reaction is generated that forces the particles to separate again. Also the container surface is covered by such a thin boundary zone. The container size is gradually reduced until the w/c ratio is achieved, whereupon motion stops.

The major compounds of the PC and of the mineral admixture (basically $\mathrm{SiO}_{2}$ representing RHA) are reacting according to standard chemical equilibrium reactions that also involve volume changes. Once the original size of the $\mathrm{PC}$ grains is exceeded after formation of $\mathrm{CSH}_{\text {in }}$ layer, deposition in smooth layers of $\mathrm{CSH}_{\text {out }}$ is continuing, thereby expanding the particles and leading to complicated interactions among hydrating neighbouring particles. This is modelled in XIPKM. Set up and verification results are shown in Figs. 1 and 2.

Pore characteristics in 3D virtual hydrated cementitious paste are investigated by the DRaMuTS method that has been introduced in Stroeven et al. By this method, randomized data structures are built incrementally in two stages. The first stage is to rapidly explore the pore space; a system of virtual trees, which consist of nodes and lines connecting pairs of such nodes (like branches in real trees), randomly and increment-tally grow in the pore medium. To speed up the process, deviating from algorithms developed in robotics, a point is shifted to avoid rejections, thereby however violating the uniform randomness of the tree system. When neighbouring trees are developing in the same pore, they will merge. In the second stage, a system of probing points is generated uni-formly at random (UR) in pore space. As a result, such points can be used for statistical assessment of pore characteristics in which point classifications are realized by connections of such points to the tree systems. For example, the connected fraction of pores can be estimated by the fraction of the total number of points that can be associated with the percolated tree branches. 

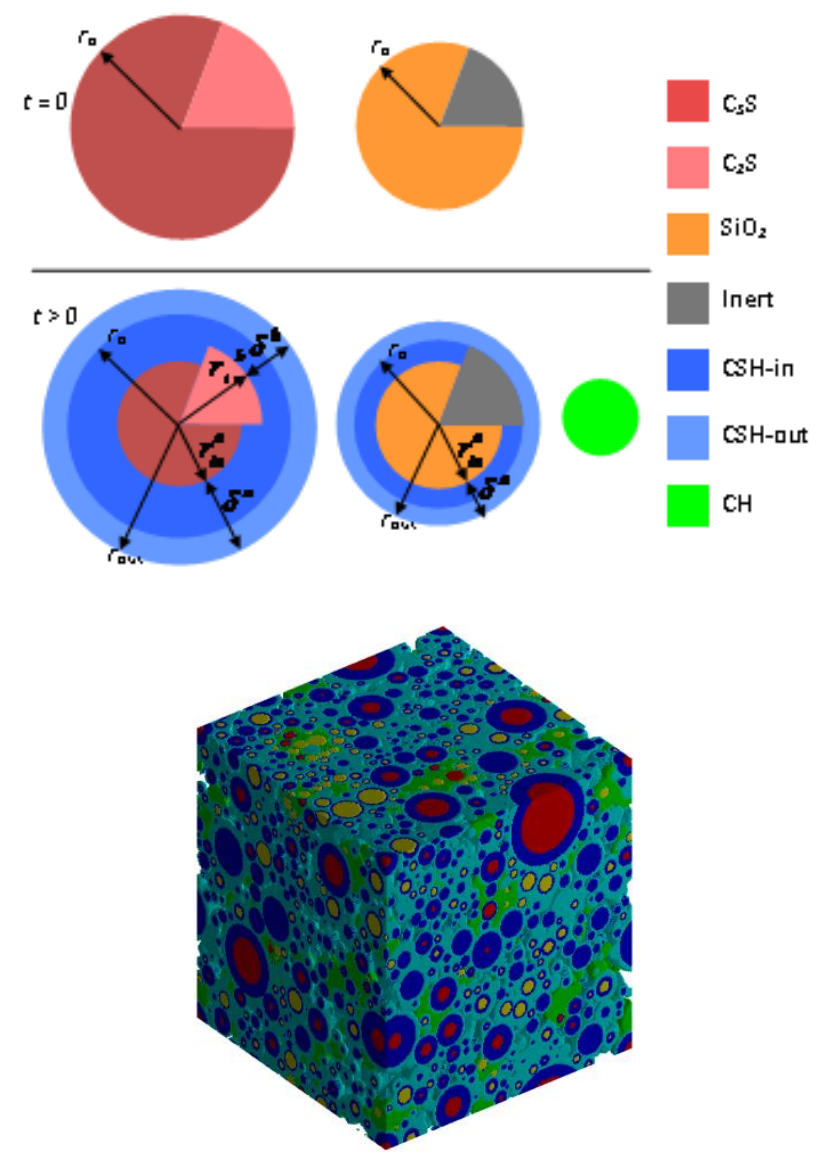

Fig. 1: (top) particle models of 2-compound cement, pozzolanic admixture and hydration product; (bot-tom) differently color-coded microstructure.

Pore size distribution (PoSD) is obtained from SVM where the system of UR points is employed as the nuclei of "stars". In each point a system of pikes is generated isotropic uniformly at random (IUR) or in systematic directions. Length of a pike, $l_{\mathrm{i}}$, spanning in an unobstructed way the distance from the star's nucleus to the nearest pore surface, is assessed. In $3 \mathrm{D}$ space, $d_{\mathrm{i}}=2 \sqrt[3]{l_{\mathrm{i}}^{3}}$, whereby $d_{\mathrm{i}}$ is an unbiased estimate of local pore size. Such star volume measurements (SVM) in the star nuclei provide the information for the construction of the $3 \mathrm{D}$ volume-based pore size distribution. Alternatively, a plane is located through a nucleus and pikes are, e.g., designed in uniform directions in the plane section. The area of this pore section is estimated by $A_{\mathrm{i}}=\pi \overline{l_{1}^{2}}$, with $l_{\mathrm{i}}$ as the unobstructed distance from the nucleus to the nearest pore perimeter. By rotating the plane section, the minimum value of $A_{\mathrm{i}}$ can be determined. This is denoted the pore throat. The aforementioned adjust-ment of sensitivity to a relevant engineering level involves eliminating all throat areas smaller than a minimum value.
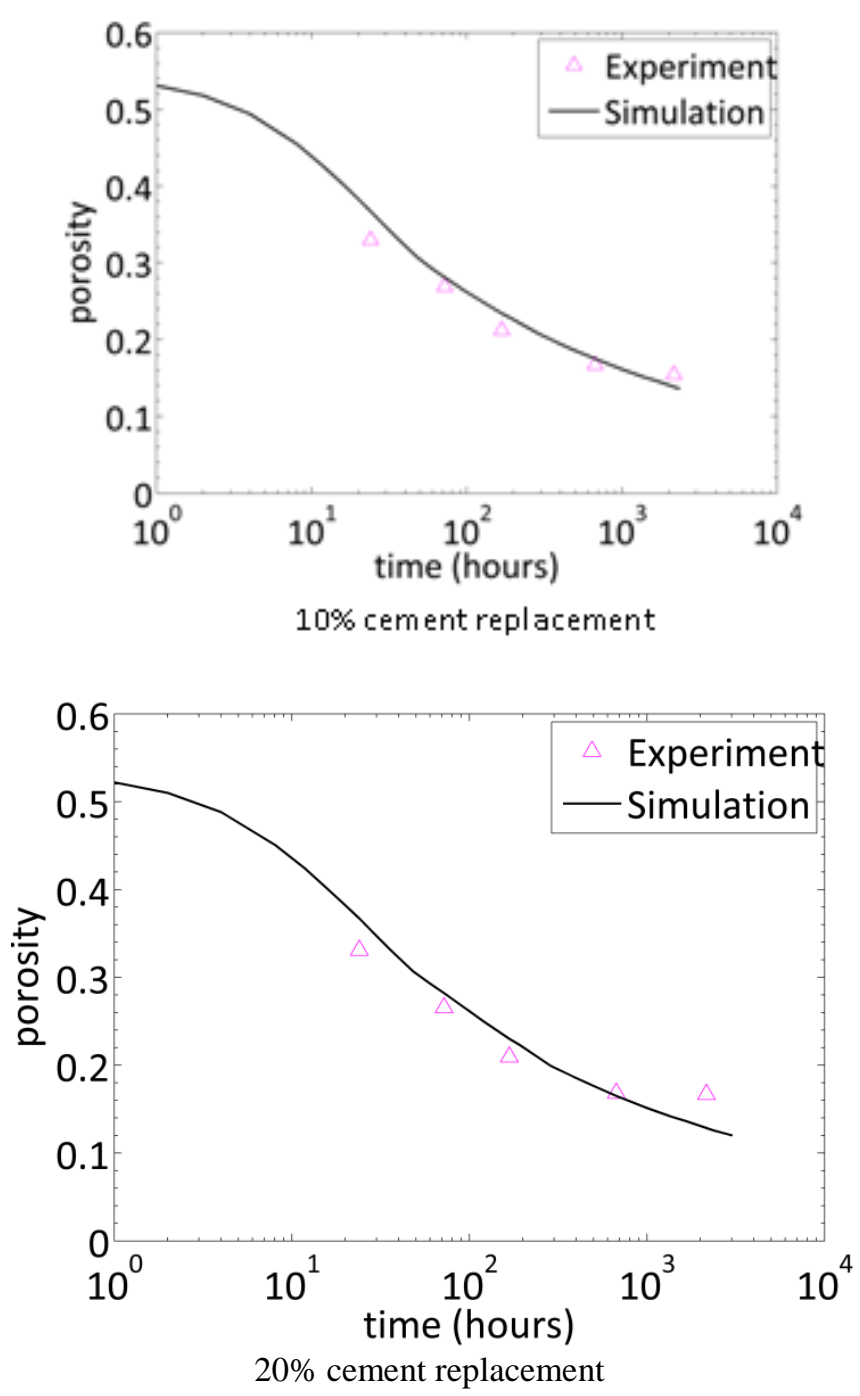

Fig. 2: Porosity of the RHA-blended PC samples (for experimental results, see Nguyen [27]. RHA-blended PC samples with $w / b=0.4$ and $10-20 \%$ replacement). Hydrated with XIPKM.

When the trees in DRaMuTS span the full dimensions of the cube, the so-called "main trunks" are extracted from the tree system. Such main trunks represent the direct paths (tracks) through pore space from the bottom to the top of the sample. Next, the main trunks are smoothed to reflect the flow length. Illustrations of main trunk extraction and smoothing are shown in Fig. 3. This extraction defines the skeleton of the pore network. For other methods for skeletonization, see [28-29]. 


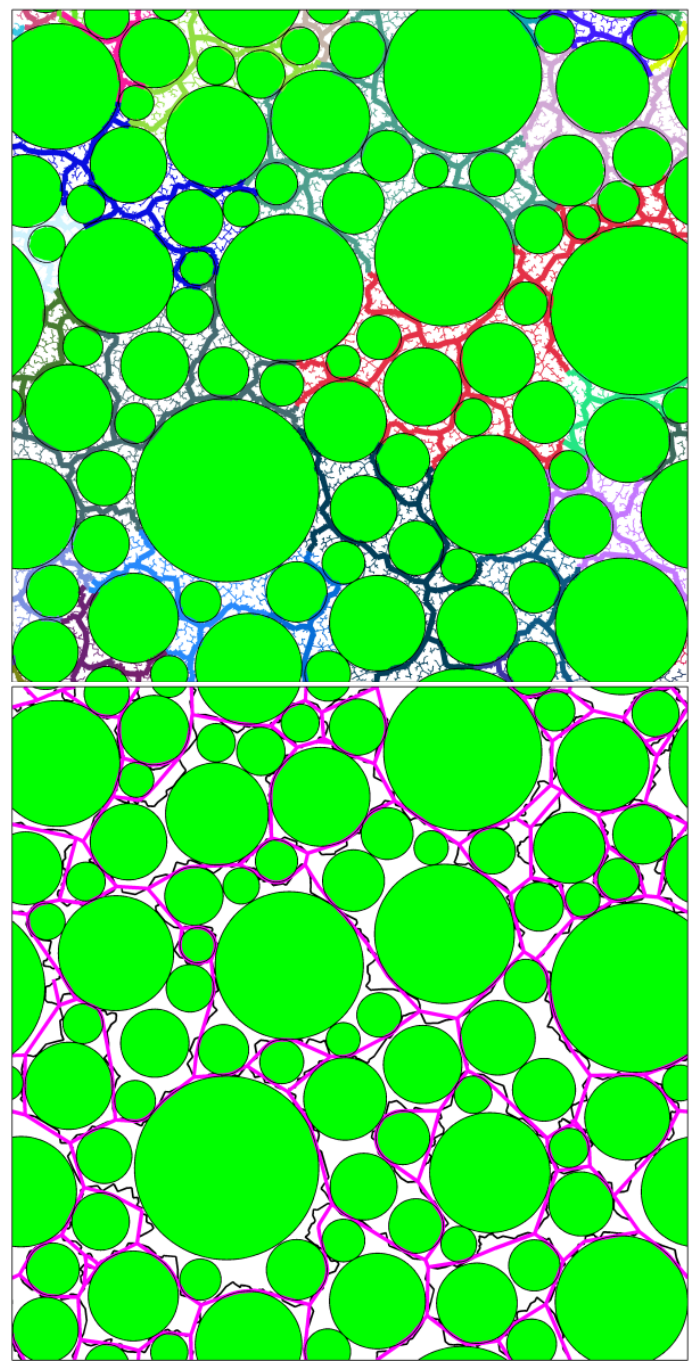

Fig. 3: (top) Picture of main trunks in 2D (bold lines) that are derived from tree branches; (bottom) Picture at the right shows trunks after smoothing.

Finally, a network structure of cylindrical tubes and nodes is constructed to represent the smoothed main trunks. The diameters of the tubes are derived from SVM along the length of the main trunks. The flow inside a tube is assumed to be slow, saturated, incompressible and laminar according to the Hagen-Poiseuille law. This structure is supposedly subject-ed to a given pressure gradient between at inlet and outlet nodes. Applying the volume conservation law at nodes between two or more tubes, a set of algebraic equations is obtained with nodal pressures as unknowns. After solving this set of equation, the permeability is estimated by Darcy's equation:

$$
K=\frac{\mu\langle u\rangle L}{\Delta P}
$$

where $K=$ permeability $\left[\mathrm{m}^{2}\right],\langle u\rangle=$ average velo-city $[\mathrm{m} / \mathrm{s}], L=$ sample length $[\mathrm{m}], \mu=$ dynamic viscosity of the intruding fluid $\left[\mathrm{N} . \mathrm{s} / \mathrm{m}^{2}\right]$, and $\Delta P=$ applied pressure gradient $\left[\mathrm{N} / \mathrm{m}^{2}\right]$.

\section{ILLUSTRATIVE BLENDING EXAMPLES}

\subsection{Materials and Experimental}

Reference PC composition: $100 \% \quad \mathrm{C}_{3} \mathrm{~S}$. Blaine fine-ness $300 \mathrm{~m}^{2} / \mathrm{kg}$. Rosin-Rammler particle size distribution with a $=1.107$ and $\mathrm{b}=0.023$. The following $\mathrm{PC}$ fractions are taken from this reference cement.
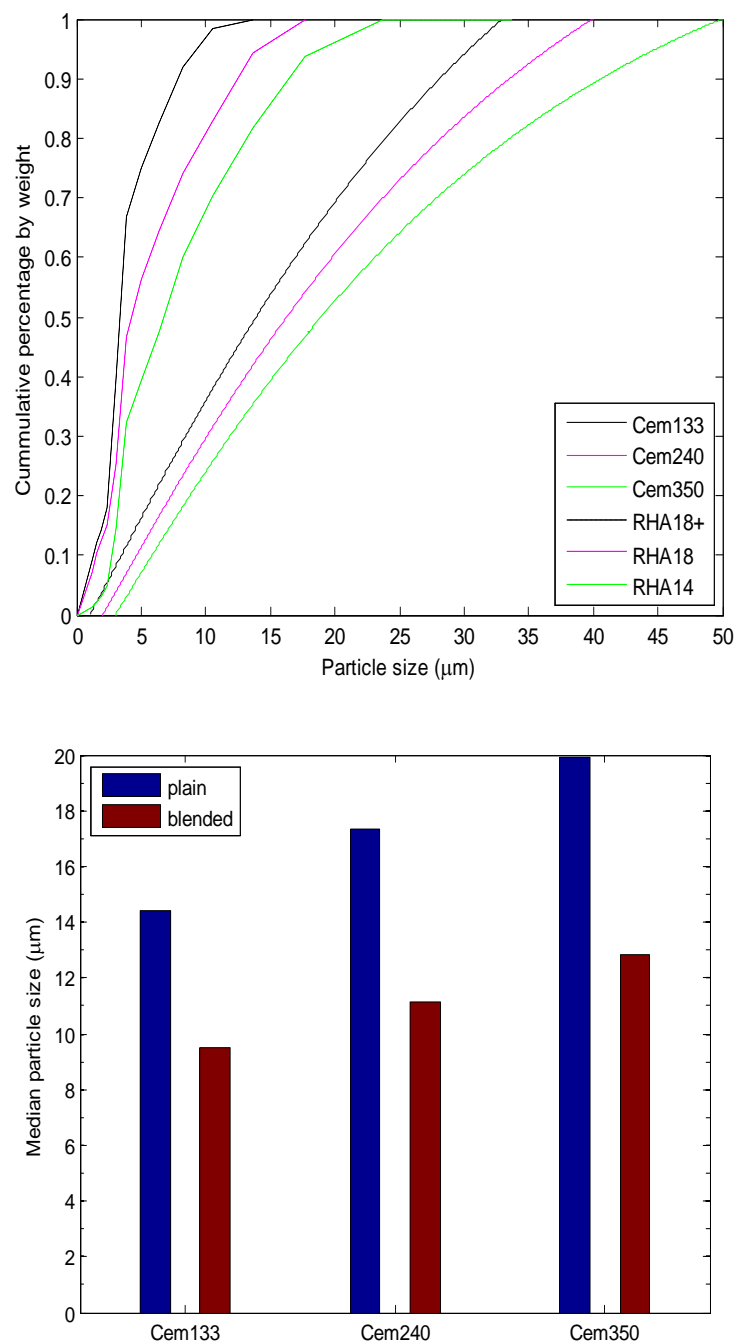

Fig. 4: (top) PSD of the materials: Portland cement (PC) and rice husk ash (RHA). (bottom) Median particle sizes of various blended mixtures (w/b=0.4, RHA $18,20 \%$ replacement)

Cem133, Cem240 and Cem350 with size ranges 1 33 $\mu \mathrm{m}$, 2 40 $\mu \mathrm{m}$ and 3 50 $\mu \mathrm{m}$, respectively. RHA: $\mathrm{SiO}_{2}$ and inert component [8,30]; RHA14: grinding time 14 h; RHA18: grinding time $18 \mathrm{~h}$; RHA18+: grinding time $18 \mathrm{~h}$ with grinding aid. Cubic samples of (blended) PC are simulated with 100-150 $\mu \mathrm{m}$ side length and two opposite rigid boundaries and four periodic ones.

Purpose is to have cements with different fineness partially replaced by rice husk ashes of different fineness that resulted from modified grinding procedure. Result is gap- 
grading to different degrees. Fig. 4 displays the particle size distributions (PSD) of the blending components. Mixtures will have as a result different median particle size as shown in Fig. 4 at the right. The effect of the resulting "gap" on pore refinement and ITZ reduction due to blending will be investigated.

\subsection{Results}

Fig. 5 shows the network of delineated pores (top) and of the main trunks connecting opposite outer surfaces of the specimen.

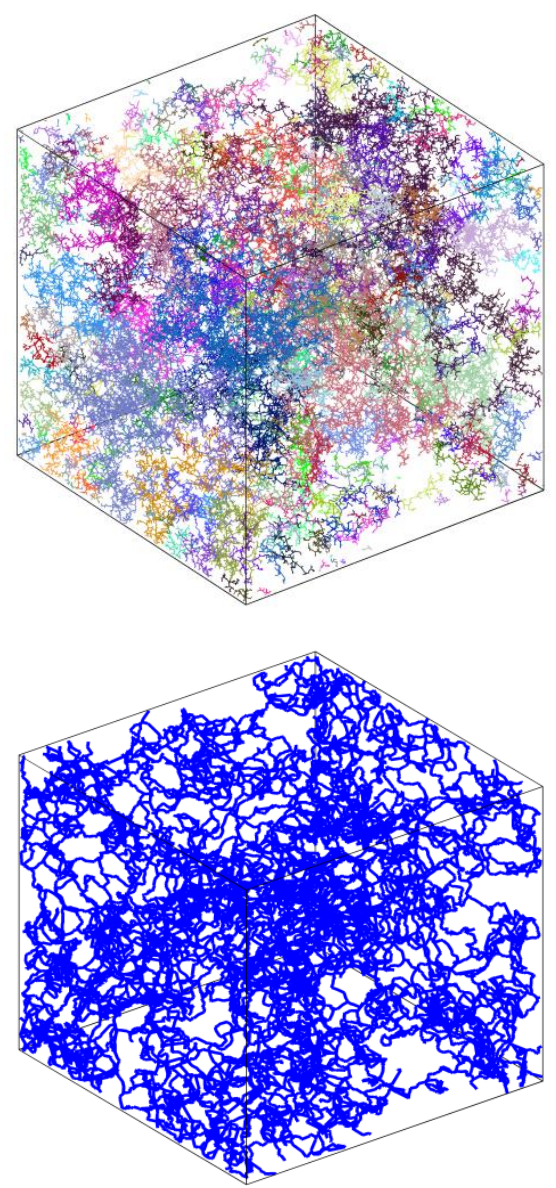

Fig. 5: Pore delineation in $100 \mu \mathrm{m}$ cubes for a plain PC sample. All trees growing in capillary pores are shown (top) as well as the extracted main trunks only (bottom). Visually similar results were obtained for blended specimens.

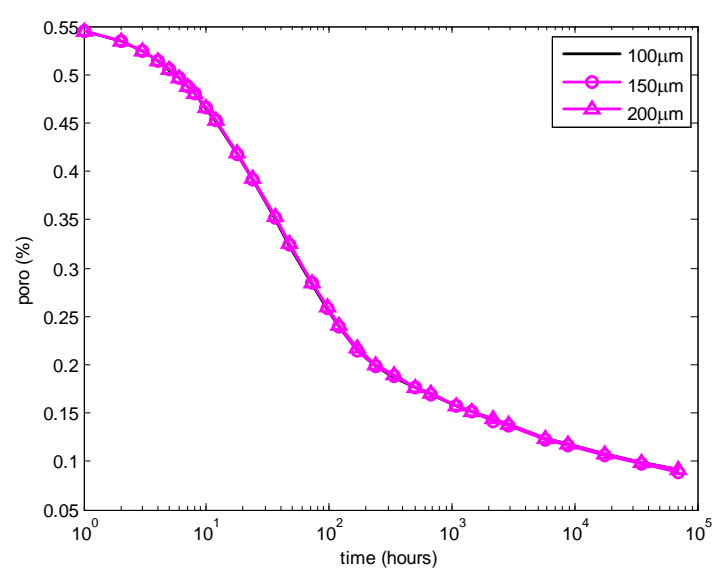

Fig. 6: Porosity evolution in time by hydration of cubic samples with different side lengths (cement size range of 3 $\sim 33 \mu \mathrm{m}$; six periodic boundaries)
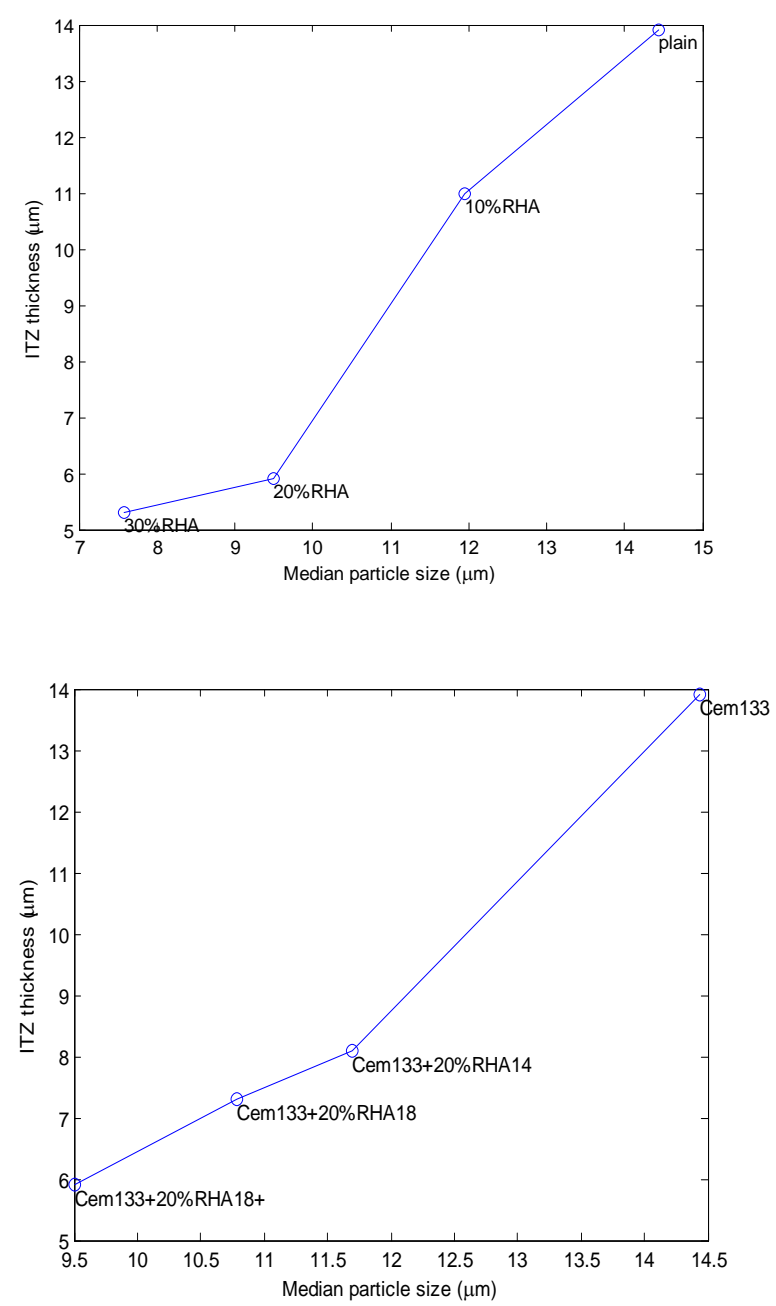

Fig. 7: ITZ thickness versus median particle size of samples with different blending dosage of RHA (Cem133, w/b = 0.4 and RHA18+) (top) and with different type of RHA

(Cem133, w/b $=0.4$ and $20 \%$ blending) (bottom).

Fig. 6 demonstrates the $100 \mu \mathrm{m}$ cube of representative size for pore evolution. This was also confirmed on the basis of other parameters in the experimental approach. Figs. 7 and 8 
demonstrate the ITZ reduced and its pore fraction diminished with increasing the size of the gap, whereas the ITZ in plain cement contains relatively high fraction of larger pores. Figs. 9 and 10 witness the pore refinement that occurs due to increasing gap-grading.
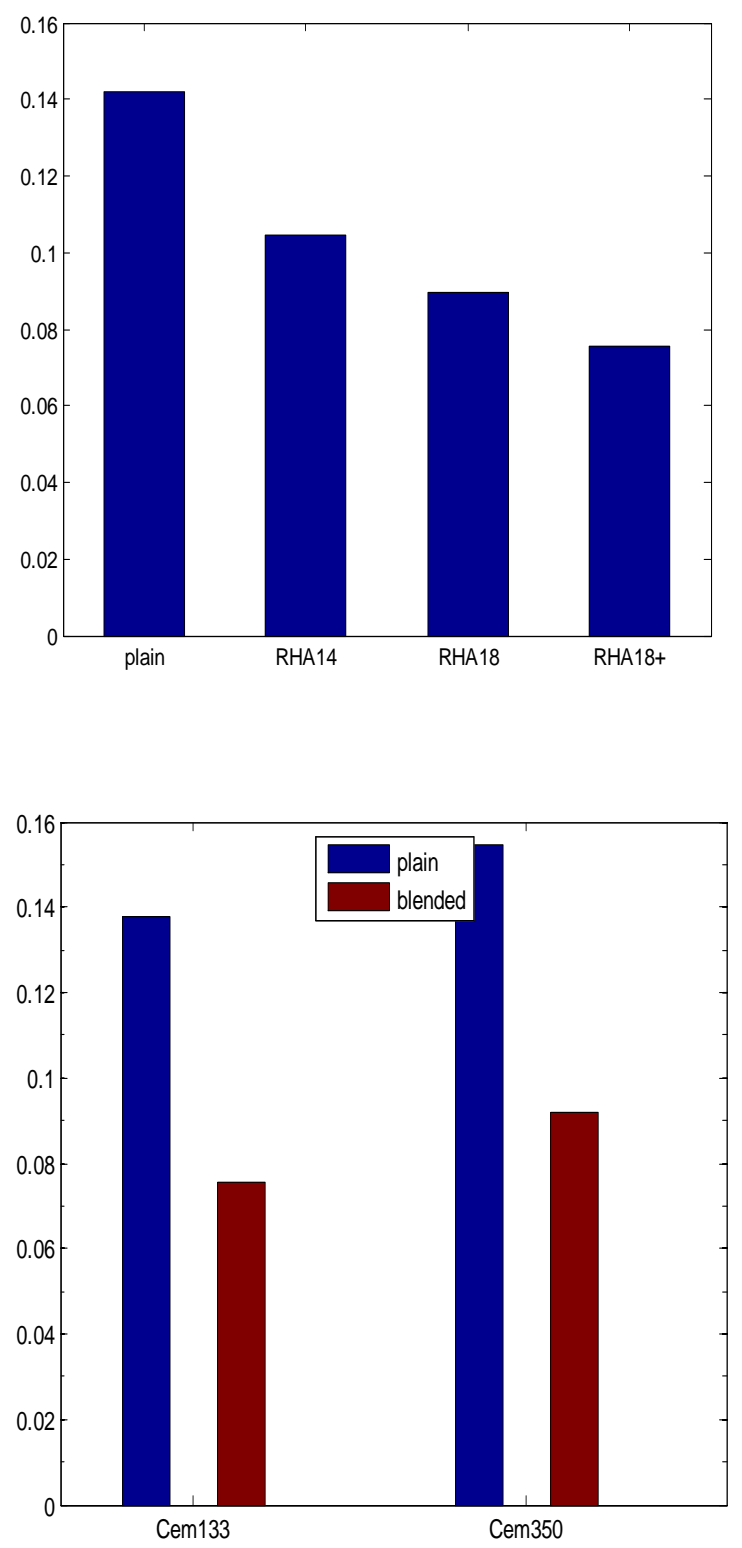

Fig. 8: Pore fraction in ITZ of samples with different type of RHA (Cem133, w/b $=0.4$ and $20 \%$ blending) (top) and with different cements fineness $(\mathrm{w} / \mathrm{b}=0.4, \mathrm{RHA} 18+$ and $20 \%$ blending)
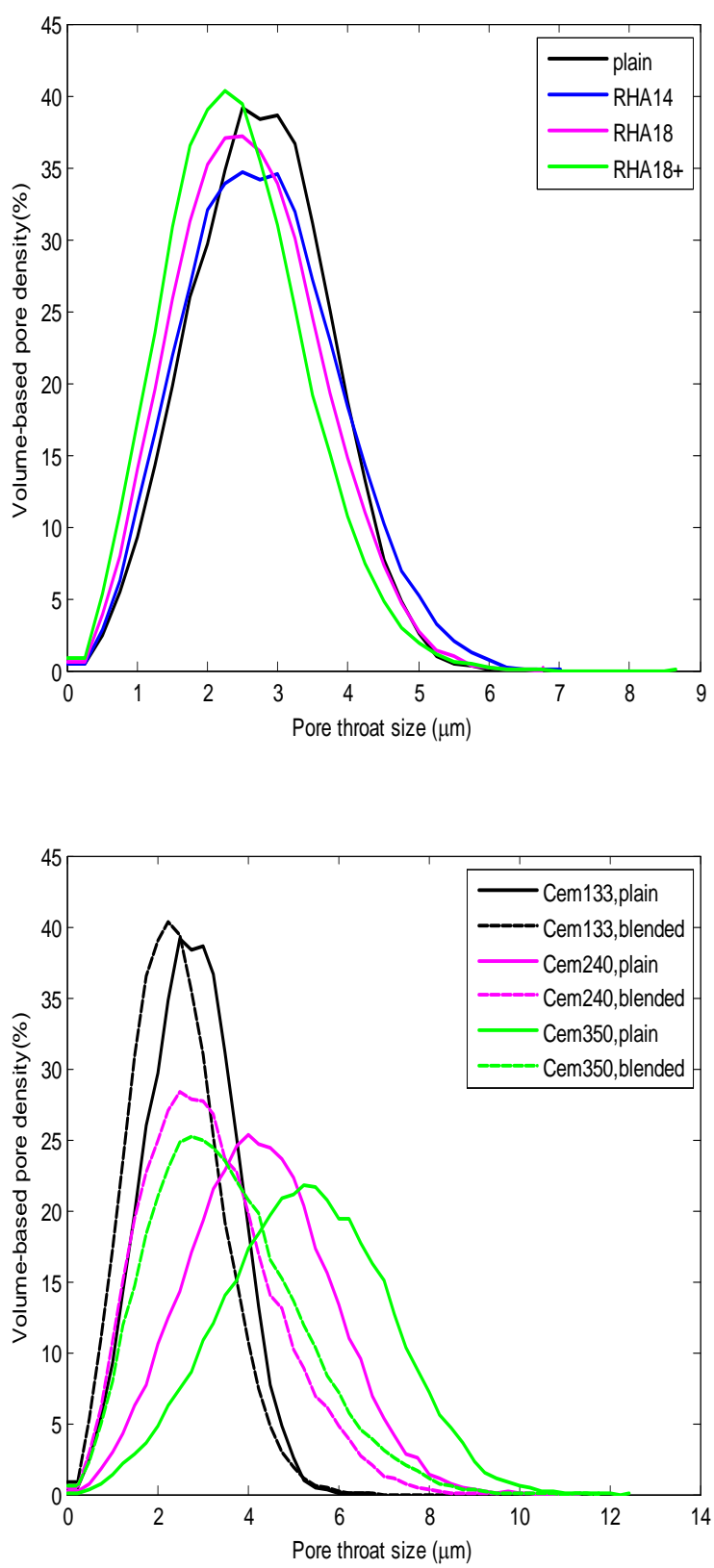

Fig. 9: Pore throat size distribution of samples with different type of RHA (Cem133, w/b $=0.4$ and $20 \%$ blending) (left) and of plain and blended samples with different cement size ranges $(\mathrm{w} / \mathrm{b}=0.4, \mathrm{RHA} 18+$ and $20 \%$ blending) (right).

\section{CONCLUSIONS}

The presented methodology offers a reliable and economic way to study in a systematic way transport-based durability issues, since the underlying pore network topology and geometry can readily be obtained. In designing monoblends or hybrid ones, fineness is a leading parameter.

Particularly in the high performance range, van der Waals contributions to strength can be significant when particle packing is improved/optimized by blending. Packing optimization exceeds the importance of the degree of pozzolanity. 

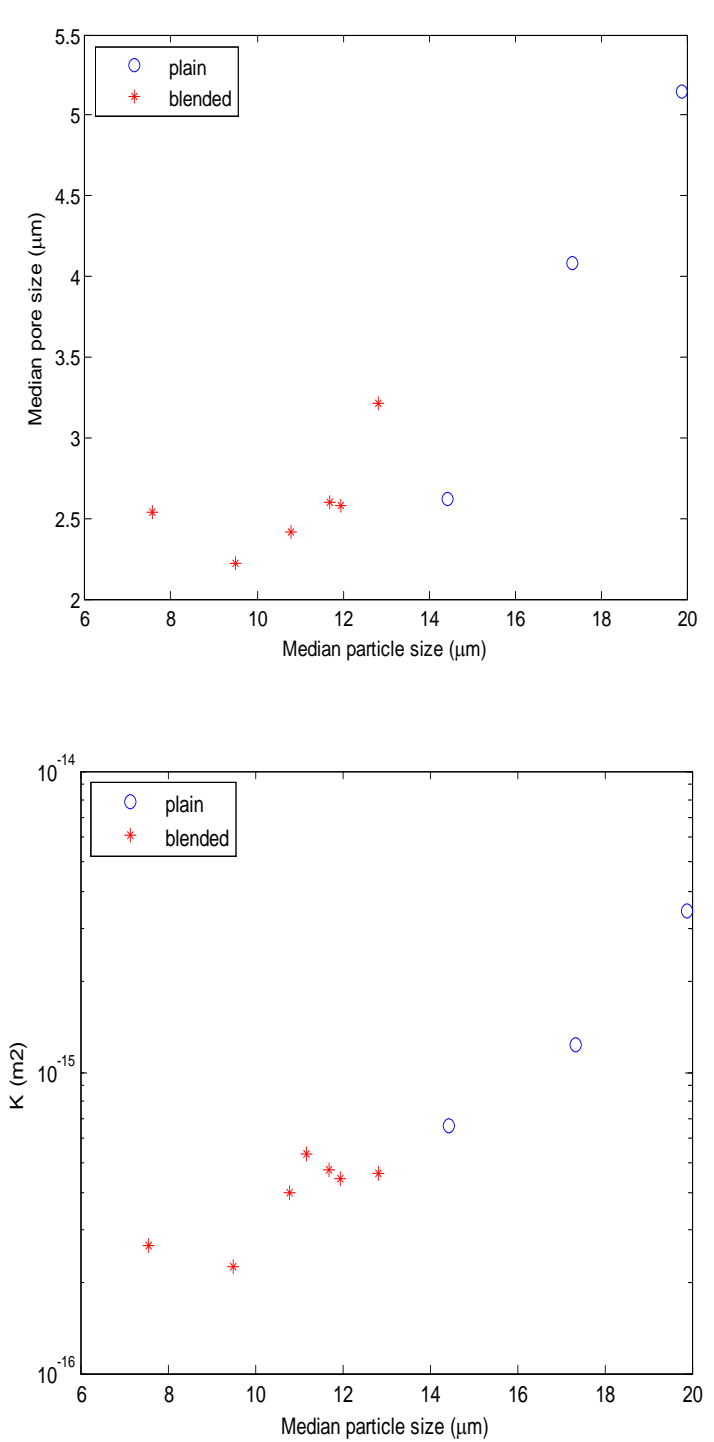

Fig. 10: Median pore size and permeability $K$ vs. median pore size of plain and blended samples (data are collected from different samples with $\mathrm{w} / \mathrm{b}=0.4)$.

\section{REFERENCES}

[1]. P. Stroeven and L.B.N. Le (2013). "Evaluation by discrete element method (DEM) of gap-graded packing potentialities for green concrete design", In: Int. Conf. Sustainable Built Environment for Now and the Future Hanoi, Vietnam, Constr. Publ. House, 347-354.

[2]. P. Stroeven, M. Stroeven and D.D. Bui (2002). "Design principles of particle packing; application to supplementary cementing materials", In: Innovations in design with emphasis on seismic, wind and environ-mental loading; quality control and innovations in materials/hot-weather concreting. ACI 5th Int. Conf. Supplementary papers, Farmington Hills, ACI, 43-60

[3]. P. Stroeven and D.D. Vu (1998). "Strength of diatomiteand kaolin-blended Portland cement pastes and concretes", In: Material Science and Concrete Properties, 1st Int. Meeting, Toulouse, France, INSA, Toulouse, 11-18
[4]. A. Goldman and A. Bentur (1993). "The influence of microfillers on enhancement of concrete strength", Cem. Concr. Res., 23, 962-972

[5]. D.D. Vu and P. Stroeven (1999). "Experiment on magnesium sulphate resistance of calcinated kaolin-blended cement mortars", In: Proc, 5th Int. Conf. Concrete Technology for Developing Countries, Nat. Council Cem. Build. Mat., Vol. I, New Delhi, IV53-IV62.

[6]. D.D. Vu, P. Stroeven and V.B. Bui (2001). "Strength and durability aspects of calcined kaolin-blended Portland cement mortar and concrete", Cem. Concr. Compos., 23, 471-478.

[7]. J. Hu and P. Stroeven (2005). "Depercolation threshold of porosity in model cement: approach by morphological evolution during hydration", Cem. Concr. Compos., 27, 1925 .

[8]. D.D. Bui, J. Hu and P. Stroeven (2005). "Parti-cle size effect on the strength of rice husk ash blended gap-graded Portland cement concrete", Cem. Concr. Compos., 27, 357366.

[9]. D.P. Bentz (1999). "Modelling cement micro-structure: Pixels, particles, and property prediction", Mater. Struct., 32, 187-195.

[10]. D.P. Bentz and E.J. Garboczi (1991). "Perco-lation of phases in a three-dimensional cement paste microstructural model", Cem. Concr. Res., 21, 325-344

[11]. D.P. Bentz, O.M. Jensen, A.M. Coats and F.P. Glasser (2000). "Influence of silica fume on diffusivity in cementbased materials: I. Experimental and computer modeling studies on cement pastes", Cem. Concr. Res., 30, 953-962.

[12]. P. Navi and C. Pignat (1996). "Simulation of cement hydration and the connectivity of the capillary pore space", Adv. Cem. Based Mater., 4, 58-67.

[13]. C. Pignat, P. Navi and K. Scrivener (2005). "Simulation of cement paste microstructure hydration, pore space characterization and permeability determi-nation", Mater. Struct., 38, 459-466.

[14]. P. Stroeven, L.B.N. Le, L.J. Sluys and H. He (2012). "Porosimetry by double random multiple tree structuring", Image Anal. Stereol., 31, 55-63.

[15]. P. Stroeven, L.B.N. Le, L.J. Sluys and H. He (2012). "Porosimetry by random node structuring in virtual concrete", Image Anal. Stereol., 31, 79-87.

[16]. P. Stroeven, J. Hu and M. Stroeven (2009). "On the usefulness of discrete element computer modeling of particle packing for material characterization in concrete technology", Comput. Concr., 6, 133-153.

[17]. P. Stroeven, J. Hu and H. Chen (2008). "Stochastic heterogeneity as fundamental basis for the design and evaluation of experiments", Cem. Concr. Compos., 30, 506514.

[18]. S.R. Williams and A.P. Philipse (2003). "Random packings of spheres and spherocylinders simu-lated by mechanical contraction", Phys. Rev. E. Stat. Nonlin. Soft. Matter. Phys. , 67, 1-9.

[19]. H. He, L.B.N. Le and P. Stroeven (2013). "Concrete's aggregate structure and its microstructure evolution investigated by DEM - Part 1", Heron, (in print),

[20]. M. Stroeven (1999). "Discrete numerical modelling of composite materials - application to cemen-titious 
materials", PhD Thesis, Delft University of Technology, Delft, 1999.

[21]. P. Stroeven and M. Stroeven (2001). "Recon-structions by SPACE of the Interfacial Transition Zone", Cem. Concr. Compos., 23, 189-200.

[22]. N.L.B. Le, M. Stroeven, L.J. Sluys and P. Stroeven (2013). "A novel numerical multi-component model for simulating hydration of cement", Comput. Mater. Sci., 78, $12-21$.

[23]. H.J.G. Gundersen, P. Bagger, T.F. Bendtsen, S.M. Evans, L. Korbo, N. Marcussen, A. Møller, K. Nielsen, J.R. Nyengaard, B. Pakkenberg, F.B. Sørensen, A. Vesterby and M.J. West (1988). "The new stereological tools: Disector, fractionator, nucleator and point sampled intercepts and their use in pathological research and diagnosis", APMIS, 96, 857-881.

[24]. P. Navi and C. Pignat (1999). "Three-dimen-sional characterization of the pore structure of a simulated cement paste", Cem. Concr. Res., 29, 507-514.

[25]. H.J. Vogel (2000). "A numerical experiment on pore size, pore connectivity, water retention, permea-bility, and solute transport using network models", Eur. J. Soil. Sci., $51,99-105$.

[26]. J. Hu (2004). "Porosity in concrete - morphological study of model concrete", PhD Thesis, Delft University of Technology, Delft, 2004.

[27]. V.T. Nguyen (2011). "Rice husk ash as a mineral admixture for ultra high performance concrete", PhD Thesis, Delft University of Technology, Delft, 2011.

[28]. W.B. Lindquist, S.-M. Lee, D.A. Coker, K.W. Jones and P. Spanne (1996). "Medial axis analysis of void structure in three-dimensional tomographic images of porous media", J. Geophys. Res.: Solid Earth, 101, 82978310.

[29]. D.B. Silin and T.W. Patzek (2003). "Robust determination of the pore space morphology in sedimentary rocks", In: SPE Annual Technical Confe-rence and Exhibition, Colorado, Society of Petroleum Engineers [30]. D.D. Bui (2001). "Rice husk ash as a mineral admixture for high performance concrete", $\mathrm{PhD}$ Thesis, Delft University of Technology, Delft, 2001.

\section{BIOGRAPHIES}

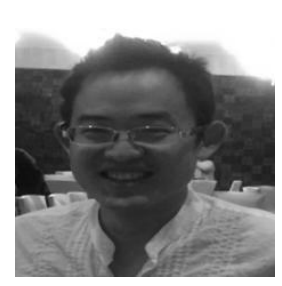

Obtained his MSc from Ho Chi Minh City University, Vietnam. Presently, $\mathrm{PhD}$ candidate in Computational Mechanics group at Delft University of Technology. His research interests focus on computational modelling of construction materials and structures

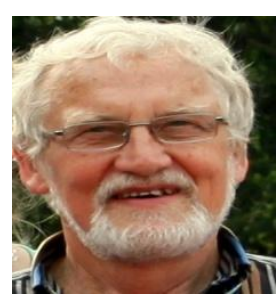

Retired Professor in Material Engineering and Delft University of Technology where he also received his $\mathrm{PhD}$. He published widely in areas ranging from structural engineering to materials science, predominantly in the concrete field 